\title{
Simple-Structured Phosphorescent Warm White Organic Light-Emitting Diodes with High Power Efficiency and Low Efficiency Roll-off
}

Jiaxiu Wang, ${ }^{\dagger}$ Jiangshan Chen, ${ }^{\dagger}$ Xianfeng Qiao, ${ }^{\dagger}$ Saad M. Alshehri, ${ }^{\S}$ Tansir Ahamad, ${ }^{\S}$ and Dongge $M a^{*}+\dot{t}, \dot{t}$,

$\uparrow$ State Key Laboratory of Polymer Physics and Chemistry, Changchun Institute of Applied Chemistry, University of Chinese Academy of Sciences, Changchun, 130022, People's Republic of China.

\$State Key Laboratory of Luminescent Materials and Devices, Institute of Polymer

Optoelectronic Materials and Devices, South China University of Technology, Guangzhou, 510640, People’s Republic of China.

§Department of Chemistry, King Saud University, Riyadh, Kingdom of Saudi Arabia

\section{AUTHOR INFORMATION}

\section{Corresponding Author}

*E-mail: mdg1014@ciac.ac.cn 


\section{Experimental Methods}

All devices were fabricated on glass substrates pre-coated with a $170 \mathrm{~nm}$ thick indium tin oxide (ITO) layer that has a sheet resistance of $10 \Omega$ square $^{-1}$. The ITO substrates were degreased in an ultrasonic solvent bath and then dried at $110{ }^{\circ} \mathrm{C}$ for 30 minutes. Before loading into the deposition chamber, the ITO surface was treated with UV-ozone for 15 minutes. All the layers were grown in succession by thermal evaporation without breaking the vacuum $\left(5 \times 10^{-4} \mathrm{~Pa}\right)$. The organics and metal oxide were evaporated at a rate in the range of $1-2 \AA \mathrm{s}^{-1}$, except for the evaporation rate of the ultra-thin layer (0.01-0.02 $\left.\AA \mathrm{s}^{-1}\right)$, and the metals were evaporated at a rate of 8-10 $\AA \mathrm{s}^{-1}$. The overlap between ITO and the Al electrodes was $4 \mathrm{~mm} \times 4 \mathrm{~mm}$, which is the active emissive area of the devices. The current-brightness-voltage characteristics were measured by using a Keithley source measurement unit (Keithley 2400 and Keithley 2000) with a calibrated silicon photodiode. The EL spectra were measured using a SpectraScan PR-650 spectrophotometer. All the measurements were carried out in an ambient atmosphere. 


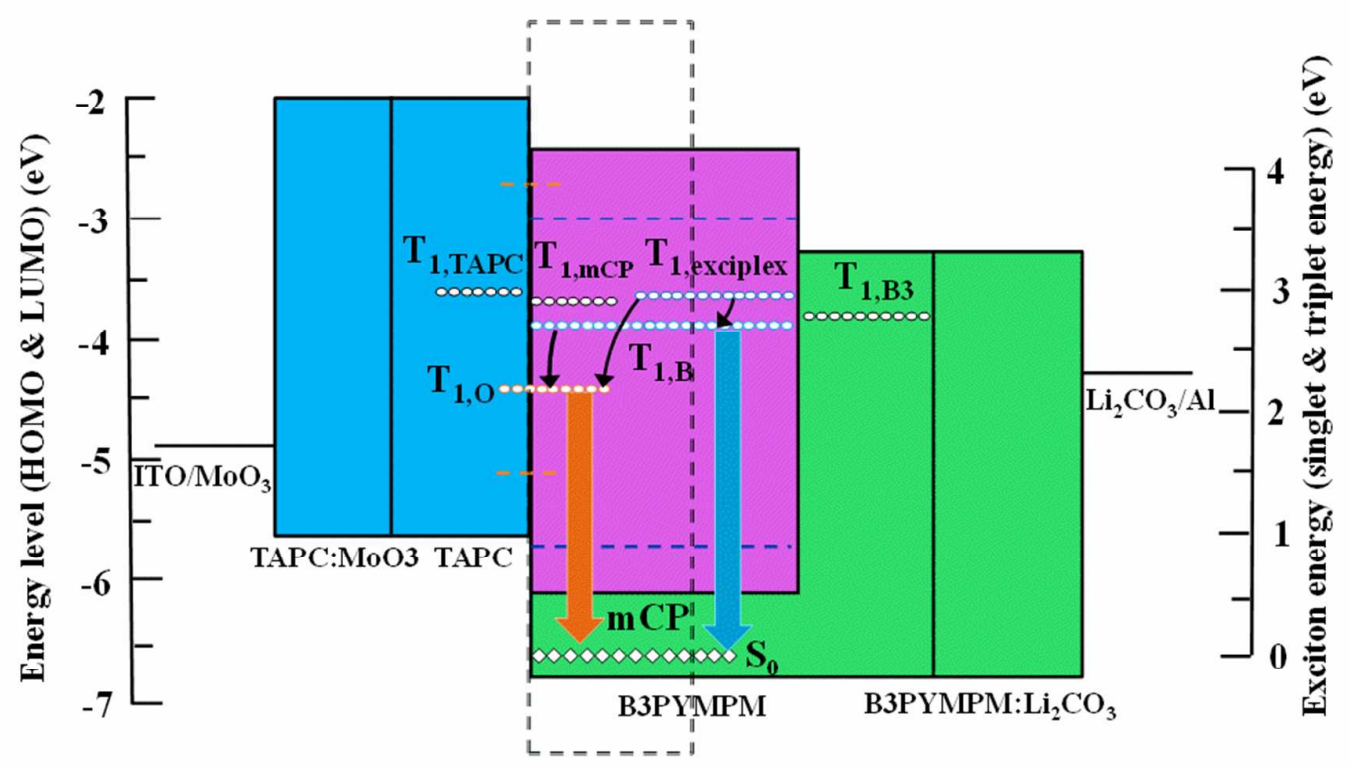

Figure S1. Device structure and energy level scheme of materials used in the resulting phosphorescent WOLEDs. The black dashed rectangle represents the main exciton recombination zone. O, B, and B3 represent PO-01, FIrpic, and B3PYMPM, respectively. The solid and dashed lines correspond to HOMO and LUMO energy levels. The circles and diamonds refer to the $T_{1}$ and $S_{0}$ exciton energies, respectively. 

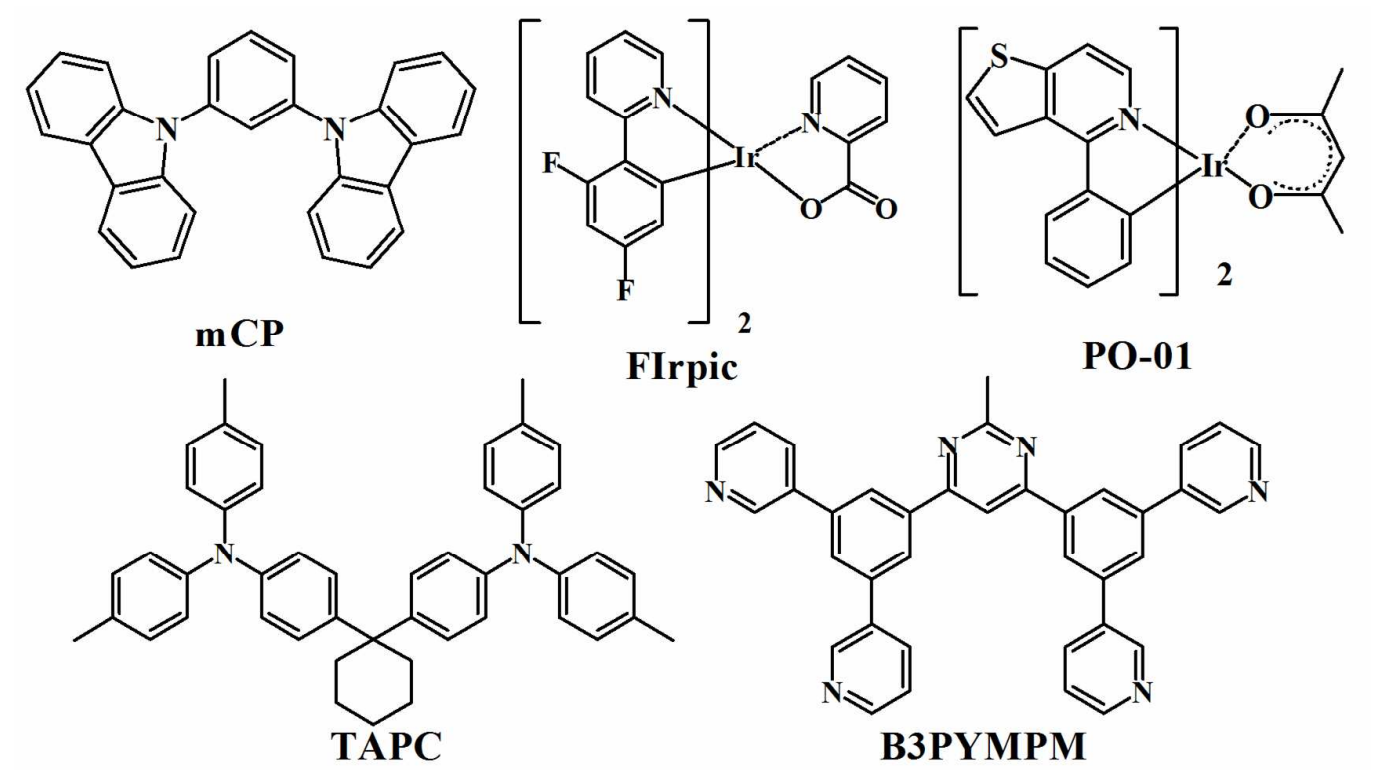

Figure S2. Chemical structures of materials used in the resulting phosphorescent WOLEDs. 

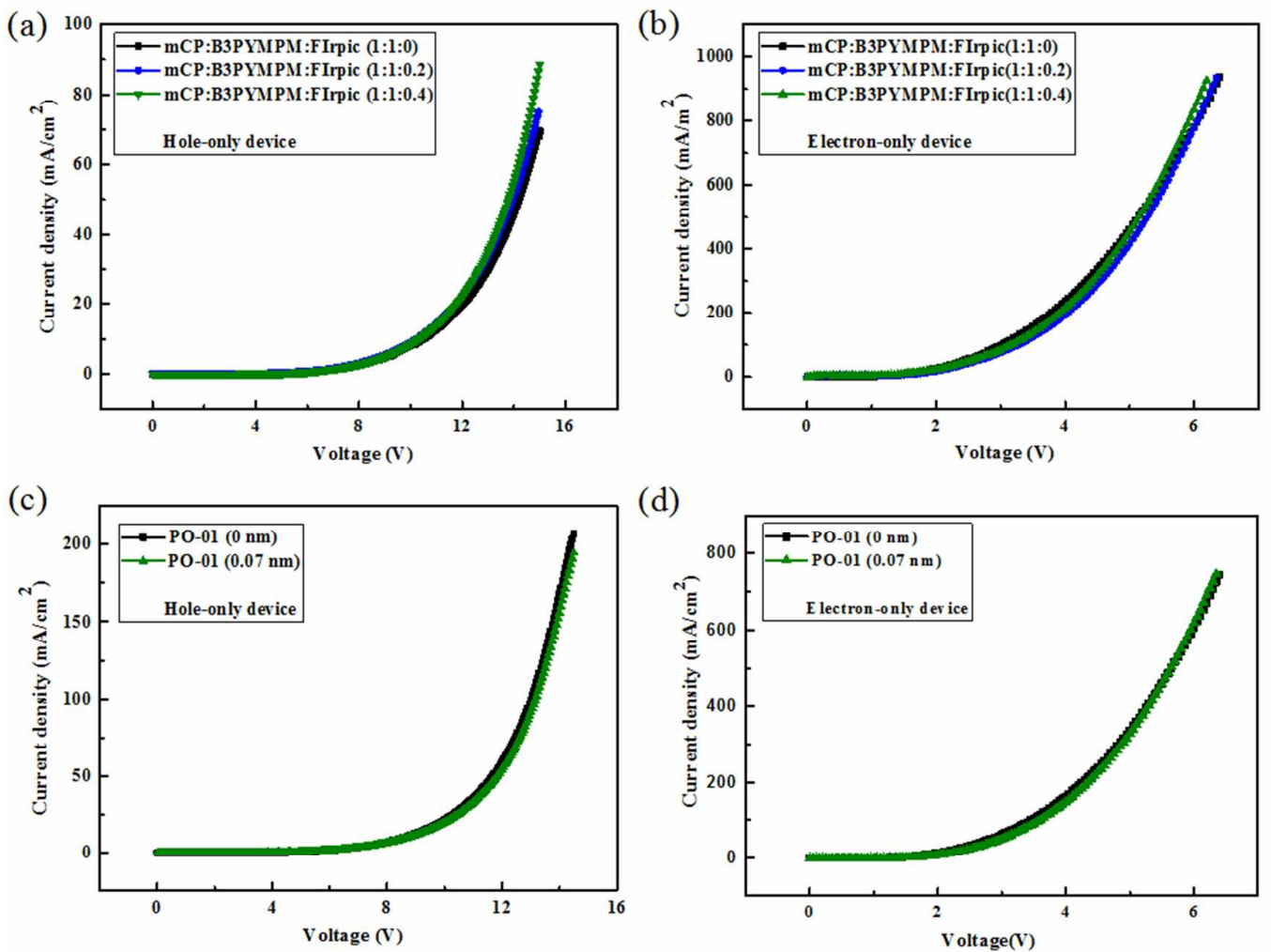

(d)

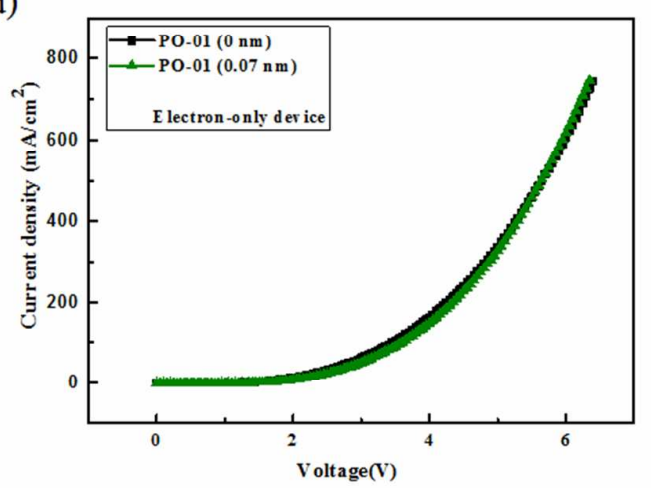

Figure S3. J-V dependence of (a) and (c) hole-only devices and (b) and (d) electron-only devices. The structures are (a) ITO/ $\mathrm{MoO}_{3}(10 \mathrm{~nm}) / \mathrm{TAPC}: \mathrm{MoO}_{3}(10 \%$, $50 \mathrm{~nm}) /$ TAPC $(20 \mathrm{~nm}) / \mathrm{mCP}:$ B3PYMPM: FIrpic (x, $10 \mathrm{~nm}) /$ TAPC $(20 \mathrm{~nm}) /$ TAPC: $\mathrm{MoO}_{3}(10 \%, 50 \mathrm{~nm}) / \mathrm{MoO}_{3}(10 \mathrm{~nm}) / \mathrm{Al}$ where $\mathrm{x}=1: 1: 0,1: 1: 0.2,1: 1: 0.4$. (b) ITO/Li $\mathrm{CO}_{3}(1 \mathrm{~nm}) / \mathrm{B} 3$ PYMPM: $\mathrm{Li}_{2} \mathrm{CO}_{3}(3 \%, 40 \mathrm{~nm}) / \mathrm{B} 3 \mathrm{PYMPM}(15 \mathrm{~nm}) / \mathrm{mCP}$ : B3PYMPM: FIrpic (x, $10 \mathrm{~nm}) / \mathrm{B} 3$ PYMPM (15 nm)/B3PYMPM: $\mathrm{Li}_{2} \mathrm{CO}_{3}(3 \%, 40$ $\mathrm{nm}) / \mathrm{Li}_{2} \mathrm{CO}_{3}(1 \mathrm{~nm}) / \mathrm{Al}$ where $\mathrm{x}=1: 1: 0,1: 1: 0.2,1: 1: 0.4$. (c) $\mathrm{ITO} / \mathrm{MoO}_{3} \quad(10$ nm)/TAPC: $\mathrm{MoO}_{3}(10 \%, 50 \mathrm{~nm}) /$ TAPC $(20 \mathrm{~nm}) /$ PO-01 (x nm)/mCP: B3PYMPM: FIrpic (1:1:0.4, $10 \mathrm{~nm}) / \mathrm{TAPC}(20 \mathrm{~nm}) / \mathrm{TAPC}: \mathrm{MoO}_{3}(10 \%, 50 \mathrm{~nm}) / \mathrm{MoO}_{3}(10 \mathrm{~nm}) / \mathrm{Al}$ where $\mathrm{x}=0,0.07$. (d) $\quad \mathrm{ITO} / \mathrm{Li}_{2} \mathrm{CO}_{3} \quad(1 \mathrm{~nm}) / \mathrm{B} 3$ PYMPM: $\mathrm{Li}_{2} \mathrm{CO}_{3} \quad(3 \%, 40$ nm)/B3PYMPM (15 nm)/PO-01 (x nm)/mCP: B3PYMPM: FIrpic (1:1:0.4, 10 
$\mathrm{nm}) / \mathrm{B} 3 P Y M P M(15 \mathrm{~nm}) / \mathrm{B} 3 P Y M P M: \mathrm{Li}_{2} \mathrm{CO}_{3}(3 \%, 40 \mathrm{~nm}) / \mathrm{Li}_{2} \mathrm{CO}_{3}(1 \mathrm{~nm}) / \mathrm{Al}$ where $\mathrm{x}=0,0.07$.

Table S1. Summary of EL performance of the fabricated blue and warm white devices (forward-viewing)

\begin{tabular}{|c|c|c|c|c|}
\hline Device & $\operatorname{Von}(\mathrm{V})^{a)}$ & $\begin{array}{l}\eta_{\mathrm{p}, \max } / \eta_{\mathrm{c}, \max } / \mathrm{EQE}_{\max }{ }^{b)} \\
\operatorname{lm} \mathrm{W}^{-1} / \mathrm{cd} \mathrm{A} \mathrm{A}^{-1} / \%\end{array}$ & $\begin{array}{l}\left.\eta_{\mathrm{p}, 1000} / \eta_{\mathrm{c}, 1000} / \mathrm{EQE}_{1000}{ }^{c}\right) \\
\operatorname{lm~} \mathrm{W}^{-1} / \mathrm{cd} \mathrm{A}^{-1} / \%\end{array}$ & $\begin{array}{l}\eta_{\mathrm{p}, 5000} / \eta_{\mathrm{c}, 5000} / \mathrm{EQE}_{5000}{ }^{d)} \\
\operatorname{lm} \mathrm{W}^{-1} / \mathrm{cd} \mathrm{A}^{-1} / \%\end{array}$ \\
\hline B1 & 3.0 & $29.4 / 28.5 / 12.6$ & $21.8 / 26.1 / 11.5$ & $17.0 / 23.1 / 10.2$ \\
\hline B2 & 2.4 & $47.1 / 40.1 / 16.8$ & $36.6 / 38.0 / 15.7$ & $23.0 / 30.1 / 12.6$ \\
\hline W & 2.4 & $75.3 / 64.5 / 20.0$ & $63.1 / 62.8 / 19.5$ & $41.1 / 52.2 / 16.2$ \\
\hline
\end{tabular}

a)The voltages estimated at $1 \mathrm{~cd} \mathrm{~m}^{-2}$; b) Maximum PE, CE and EQE; c) PE, CE, and $\mathrm{EQE}$ at $1000 \mathrm{~cd} / \mathrm{m}^{2} ;$ d) $\mathrm{PE}, \mathrm{CE}$, and $\mathrm{EQE}$ at $5000 \mathrm{~cd} / \mathrm{m}^{2}$. 